\title{
Improved Lung Cancer Detection in Cardiovascular Outpatients by the Pulmonologist-based Interpretation of Chest Radiographs
}

\author{
Mitsuaki Sakai ${ }^{1-3}$, Akinori Kato $^{3}$, Naohiro Kobayashi ${ }^{2,3}$, \\ Ryota Nakamura $^{3}$, Shuuichi Okawa ${ }^{4}$ and Yukio Sato ${ }^{2}$
}

\begin{abstract}
Objective Pulmonologists and cardiologists view chest radiographs differently. Lung cancer may therefore go undetected in patients referred to cardiovascular departments. We aimed to determine the clinical benefit of the additional interpretation of chest radiographs by pulmonologists in study involving cardiovascular outpatients.

Methods A retrospective review of chest radiographs of outpatients attending a Japanese cardiovascular hospital between April 2000 and March 2010 was conducted. Lung cancer patients were categorized into 3 groups: group C, patients in whom tumors were detected by a cardiologist at the first visit; group P, patients in whom tumors were detected by the additional interpretation of a chest radiographs by a pulmonologist after a lesion was missed by a cardiologist; and group $\mathrm{H}$, patients from an earlier period in which chest radiographs were only examined by a cardiologist.

Results Cardiologists detected 9 cases of lung cancer in groups $\mathrm{C}$ and $\mathrm{H}$ from 2,430 and 2,288 radiographs, respectively. Pulmonologists detected 10 cases of lung cancer (group P) and 3 other malignancies that were previously undetected, giving a miss rate of $52.6 \%$ for the cardiologists. Tumor diameters were significantly smaller in group $\mathrm{P}$ than in group $\mathrm{C}$ or $\mathrm{H}$. Furthermore, a significantly higher number of the tumors in group $\mathrm{P}$ were of an early stage and resectable, with more superposing structures than in groups $\mathrm{C}$ or $\mathrm{H}$.

Conclusion The additional pulmonologist-based interpretations significantly increased the detection rate of operable tumors that mostly corresponded to the early $\mathrm{T} 1$ stage; this serves offers a potential clinical benefit in reducing the period of time from patient presentation to the diagnosis of lung cancer.
\end{abstract}

Key words: cardiac outpatients, lung cancer, radiography, chest X-ray, diagnosis

(Intern Med 54: 2991-2997, 2015)

(DOI: 10.2169/internalmedicine.54.4171)

\section{Introduction}

Despite an increase in newer technologies, chest radiography is routinely used in clinical practice for the detection of lung cancer because it is cost effective, simple to perform, and involves minimal exposure of the patient to radiation. However, the analysis of chest radiographs can often lead to a "missed lung cancer" diagnosis, which may lead to medicolegal complications (1-10). Published studies have re- ported a misdiagnosis rate in the range of $12-90 \%(1,8-10)$. The length of time by which a diagnosis is delayed influences tumor growth and patient prognosis (1). Variations in diagnostic performance can be influenced by numerous factors, including the presence of inconspicuous lesions, image quality, viewing conditions, the specialty of the physicians and their experience level (1-3).

For the cardiologist, the radiographic manifestations of various cardiovascular diseases are extensively defined in the published cardiovascular literature; however, there are hardly

${ }^{1}$ Department of Thoracic Surgery, Tsukuba Medical Center Hospital, Japan, ${ }^{2}$ Department of Thoracic Surgery, Faculty of Medicine, University of Tsukuba, Japan, ${ }^{3}$ Department of Pulmonology, East Toride Hospital, Japan and ${ }^{4}$ Department of Cardiology, East Toride Hospital, Japan Received for publication September 26, 2014; Accepted for publication March 29, 2015

Correspondence to Dr. Mitsuaki Sakai, misakai@md.tsukuba.ac.jp 
Period of additional interpretation by pulmonologists (April 2005- March 2010)

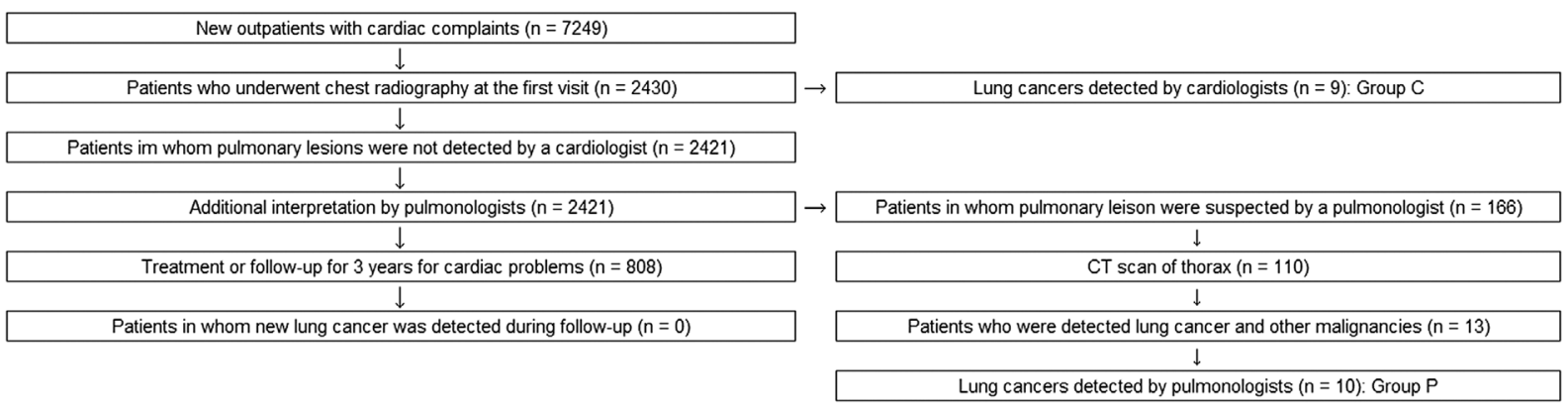

Historical control preriod of no additional interpretation (April 2000-March 2005)

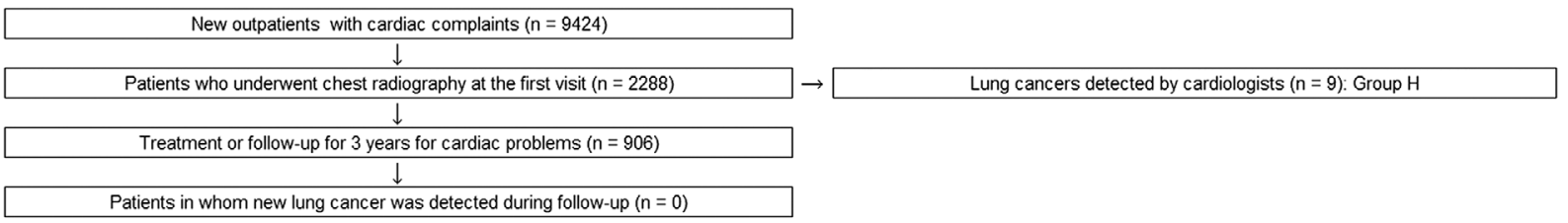

Figure 1. A flow chart showing the diagnostic algorithm for detecting lung cancer on the chest radiographs for each period.

any published reports describing the assessment of lung cancer and other pulmonary nodules from radiographs (11-15) and a cardiologist will typically assess a radiograph with a focus on identifying cardiovascular problems.

Cardiovascular disease and lung cancer partially share common characteristics, including patient age, risk factors such as smoking, and chest symptoms. A pulmonologist and cardiologist would view the same chest radiographs but would offer different interpretations. Therefore, when a chest radiograph is viewed solely by the cardiologist, the potential exists for cases of lung cancer to go undetected.

The purpose of the present investigation was (i) to determine the characteristics and frequency of undetected lung cancer in cardiovascular outpatients (who underwent chest radiography performed by a cardiologist) and (ii) to estimate the potential clinical benefit of the further interpretation of chest radiographs by pulmonologists.

\section{Materials and Methods}

This retrospective, single institutional, clinical study was conducted in new outpatients with cardiovascular complaints at a specialist cardiology hospital in the Ibaraki Prefecture, Japan between April 2000 and March 2010. This hospital employs 6 cardiologists with $>20$ years of experience. Radiologists were not in attendance at the hospital, and a remote interpretation system was not adopted. This study was approved by the institutional review board of the East Toride Hospital and individual patient consent was waived.

\section{Chest radiograph analyses}

The cardiologists routinely examined patients with cardiac complaints and performed chest radiographs at the time of the first visit. Each cardiologist evaluated the chest radio- graphs alone as a routine task. The diagnostic algorithm used to detect lung cancer is shown in (Fig. 1). Any patients with lung cancer detected using these radiographs were categorized as 'group C', which denotes detection by the cardiologist.

Two pulmonologists with $>10$ years of experience from the University of Tsukuba hospital performed an independent, blinded interpretation of chest radiographs, which had been found to be lung nodule-negative by the cardiologists. The pulmonologists then performed an interpretation as they would in routine clinical practice. Each pulmonologist evaluated all of the chest radiographs independently.

Chest computed tomography (CT) was performed in all of the patients who the pulmonologists identified as having lung abnormalities, and the detection of pulmonary lesions was made with a consensus from the two pulmonologists. Since, a disagreement in interpretation could lead to misdiagnosis and important errors $(16,17)$, any patients for whom a consensus could not be reached were also subjected to chest CT. Patients in whom lung cancer was detected by the pulmonologists alone were analyzed as 'group P.'

Between April 2000 and March 2005, patient radiographs were viewed by cardiologists alone; patients from this group were categorized as 'group H', which denoted the historical control group. Chest radiographs from revisiting patients and lateral radiographs were excluded. Follow-up was conducted between April 2010 and December 2013 in patients from groups $\mathrm{C}$ and $\mathrm{P}$ to detect the onset of new cases of lung cancer.

Chest radiographs were obtained using DR-155HM and Radnex50 (Hitachi Medical Corporation, Tokyo, Japan) Xray machines with a cassette type digital X-ray detector (REGIUS model 190, KONICA MINOLTA, Tokyo, Japan) set at $130 \mathrm{kV}, 100 \mathrm{~mA}$, with a grid ratio of 10:1 and a focus 
Table 1. Characteristics of the Patients in this Study.

\begin{tabular}{|c|c|c|c|c|}
\hline Characteristics of the patients in this study & \multicolumn{2}{|c|}{$\begin{array}{l}\text { Additional interpretation } \\
\text { period } \\
\text { April } 2005 \text { - March } 2010\end{array}$} & \multicolumn{2}{|c|}{$\begin{array}{c}\text { Historical period } \\
\text { April } 2000 \text { - March } 2005\end{array}$} \\
\hline Number of new outpatients & \multicolumn{2}{|c|}{7,249} & \multicolumn{2}{|c|}{9,424} \\
\hline Nunber of the chest radiograph & \multicolumn{2}{|c|}{2,430} & \multicolumn{2}{|c|}{2,288} \\
\hline Average age (yr) (range) & $58.0 \pm 18.0$ & $(11-95)$ & $64.5 \pm 17.1$ & $(10-99)$ \\
\hline Number of men $(\%)$ & 1,169 & $(48.1)$ & 1,061 & (46.4) \\
\hline \multicolumn{5}{|l|}{ Complaints } \\
\hline Chest pain/discomfort & 27.3 & $\%$ & 27.6 & $\%$ \\
\hline Palpitation & 14.5 & $\%$ & 14.7 & $\%$ \\
\hline Electrocardiographic abnormality & 15.3 & $\%$ & 11.3 & $\%$ \\
\hline Cough & 10.5 & $\%$ & 8.8 & $\%$ \\
\hline Dyspnea, Shortness of breath & 6.8 & $\%$ & 8.3 & $\%$ \\
\hline $\begin{array}{r}\text { Other abnormalities of the physical } \\
\text { examination }\end{array}$ & 4.1 & $\%$ & 6.1 & $\%$ \\
\hline Changing of hospital & 5.3 & $\%$ & 5.9 & $\%$ \\
\hline Vertigo, loss of consciousness & 3.4 & $\%$ & 2.9 & $\%$ \\
\hline Heart murmur & 1.1 & $\%$ & 2.3 & $\%$ \\
\hline Abdominal symptoms & 1.6 & $\%$ & 2.0 & $\%$ \\
\hline Fever & 1.6 & $\%$ & 1.6 & $\%$ \\
\hline Sore throat & 1.3 & $\%$ & 1.3 & $\%$ \\
\hline Others & 7.2 & $\%$ & 7.1 & $\%$ \\
\hline \multicolumn{5}{|l|}{ Number of doctors who did interpretation } \\
\hline Cardiologists & \multicolumn{2}{|c|}{6} & \multicolumn{2}{|c|}{6} \\
\hline Pulmonologists & \multicolumn{2}{|c|}{2} & \multicolumn{2}{|c|}{-} \\
\hline Lung cancers detected by cardiologists & \multicolumn{2}{|c|}{$9(=$ Group C $)$} & \multicolumn{2}{|c|}{9 ( = Group H) } \\
\hline
\end{tabular}

Table 2. Detected Malignancies Detected by Pulmonologists.

\begin{tabular}{|c|c|c|}
\hline & $\mathrm{n}$ & $(\%)$ \\
\hline Number of additional interpretation by the pulmonologists & 2,421 & $(100)$ \\
\hline Pulmonary and mediastinal abnormalities & 166 & $(6.9)$ \\
\hline Computed tomography of the thorax & 110 & $(4.5)$ \\
\hline \multicolumn{3}{|l|}{ Malignancies } \\
\hline Lung cancer $(=$ Group P) & 10 & $(0.42)$ \\
\hline Esophageal cancer & 1 & $(0.04)$ \\
\hline Mediastinal Lymphoma & 1 & $(0.04)$ \\
\hline Multiple cancers (pharyngeal, esophageal, and gastric cancer) & 1 & $(0.04)$ \\
\hline
\end{tabular}

film distance of $200 \mathrm{~cm}$. The clinicopathological characteristics, TNM stages, tumor distribution, and resection rates of the groups were evaluated.

\section{Statistical analyses}

Continuous variables such as age and tumor size were compared by one-way analysis of variance (ANOVA) with Bonferroni correction. The distribution of the primary site, clinical stage, histology, and the differences in the initial treatment among the groups were tested by multiple comparisons using the Kruskal-Wallis test. The data that were determined to be significantly different were further analyzed using a Mann-Whitney U test with Bonferroni correction to compare data between 2 groups (P vs. H, C vs. H, and $\mathrm{P}$ vs. C). Continuous variables were expressed as the mean $\pm \mathrm{SD}$, and a $\mathrm{p}$ value of $<0.05$ was considered to be statistically significant. All statistical analyses were conducted using the SPSS statistics 22.0 (IBM Japan, Tokyo, Japan) software program.

\section{Results}

The characteristics of the study population are summarized in Table 1. Between April 2000 and March 2005 (historical control period), 2,288 chest radiographs were taken in 9,424 consecutive new outpatients. Between April 2005 and March 2010 (interpretation period), 2,430 chest radiographs were taken in 7,249 consecutive new outpatients. Chest radiography was performed because of chest pain/discomfort, palpitations, and electrocardiographic abnormalities. In both periods, cardiologists identified 9 cases of lung cancer in each group (groups $\mathrm{C}$ and $\mathrm{H}$ ).

Pulmonologists interpreted 2,421 chest radiographs and detected $166(6.9 \%)$ pulmonary and mediastinal abnormal shadows (Table 2). Of these cases, $110(4.5 \%)$ patients underwent chest $\mathrm{CT}$, which revealed a total of 13 malignancies that were not detected by the cardiologists, including lung cancer in $10(0.42 \%)$ patients, esophageal cancer in 1 patient $(0.04 \%)$, mediastinal malignant lymphoma in 1 patient $(0.04 \%)$, and a combined case of pharyngeal, esophageal, 
Table 3. Characteristics of Detected Lung Cancers.

\begin{tabular}{|c|c|c|c|c|c|c|c|c|c|c|}
\hline \multirow{5}{*}{$\begin{array}{l}\text { Total No. } \\
\text { No.of men } \\
\text { Age, mean } \pm S D \text {, } \\
\text { yr, (range) }\end{array}$} & \multirow{2}{*}{\multicolumn{2}{|c|}{$\begin{array}{l}\text { Lung cancers } \\
\text { detected by } \\
\text { pulmonologists } \\
\text { Group P (\%) }\end{array}$}} & \multicolumn{4}{|c|}{$\begin{array}{c}\text { Lung cancers } \\
\text { detected by cardiologists }\end{array}$} & \multirow{4}{*}{$\begin{array}{c}\begin{array}{c}\text { Three } \\
\text { groups }\end{array} \\
0.457\end{array}$} & \multicolumn{2}{|c|}{$\mathrm{p}$ value } & \multirow{3}{*}{ C vs. H } \\
\hline & & & \multicolumn{2}{|c|}{ Group C (\%) } & \multicolumn{2}{|c|}{ Group H (\%) } & & P vs. H & P vs. C & \\
\hline & \multicolumn{2}{|c|}{10} & \multicolumn{2}{|c|}{9} & \multicolumn{2}{|c|}{9} & & & & \\
\hline & 5 & $(50)$ & 6 & (67) & 7 & (78) & & - & - & - \\
\hline & $71.4 \pm 10.4$ & $(49-89)$ & $71.3 \pm 9.9$ & $(61-89)$ & $68.2 \pm 14.5$ & $(40-82)$ & 0.803 & - & - & - \\
\hline Tumor size (mm) & $18.5 \pm 5.5$ & $(14-30)$ & $37.4 \pm 24.4$ & $(19-96)$ & $42.4 \pm 11.6$ & $(28-65)$ & $0.006 \S$ & $<0.000 \S$ & $0.028 \S$ & 0.587 \\
\hline \multicolumn{11}{|l|}{$\begin{array}{l}\text { Location of } \\
\text { primary tumor }\end{array}$} \\
\hline Hilar & 1 & (10) & 1 & (11) & 4 & (44) & $0.036^{*}$ & 0.159 & 1.812 & 0.093 \\
\hline Parahilar & 4 & (40) & 2 & (22) & 4 & (44) & & & & \\
\hline Peripheral & 5 & $(50)$ & 6 & (67) & 1 & (11) & & & & \\
\hline \multicolumn{11}{|l|}{ Lobe } \\
\hline Left Upper & 2 & (20) & 3 & (33) & 3 & (33) & & & & \\
\hline Left Lower & 3 & (30) & 1 & (11) & 2 & (22) & & & & \\
\hline Right Upper & 3 & (30) & 1 & (11) & 2 & (22) & 0.716 & - & - & - \\
\hline Right Middle & 1 & (10) & 0 & & 1 & (11) & & & & \\
\hline Right Lower & 1 & (10) & 3 & (33) & 1 & (11) & & & & \\
\hline Multiple & 0 & & 1 & (11) & 0 & & & & & \\
\hline \multicolumn{11}{|l|}{ Stage } \\
\hline IA & 7 & $(70)$ & 1 & (11) & 0 & & & & & \\
\hline IB & 1 & (10) & 0 & & 1 & (11) & & & & \\
\hline IIA & 0 & & 1 & (11) & 0 & & & & & \\
\hline IIB & 1 & (10) & 0 & & 0 & & $<0.000^{*}$ & $<0.000 \dagger$ & $0.003 \dagger$ & 2.589 \\
\hline IIIA & 1 & (10) & 0 & & 0 & & & & & \\
\hline IIIB & 0 & & 2 & (22) & 3 & (33) & & & & \\
\hline IV & 0 & & 5 & (56) & 5 & (56) & & & & \\
\hline $\begin{array}{l}\text { Superposing } \\
\text { structure }\end{array}$ & 8 & $(80)$ & 2 & (22) & 5 & (56) & & & & \\
\hline Vessel & 3 & (30) & 1 & (11) & 4 & (44) & $0.014^{*}$ & 0.633 & $0.030 \dagger$ & 0.774 \\
\hline Heart & 2 & (20) & 0 & & 1 & (11) & & & & \\
\hline Bone & 3 & (30) & 1 & (11) & 0 & & & & & \\
\hline \multicolumn{11}{|l|}{ Histology } \\
\hline Adenocarcinoma & 6 & $(60)$ & 8 & (89) & 4 & (44) & & & & \\
\hline $\begin{array}{r}\text { Squamous cell } \\
\text { carcinoma }\end{array}$ & 4 & $(40)$ & 1 & (11) & 2 & (22) & & & & \\
\hline $\begin{array}{l}\text { Large cell } \\
\text { carcinoma }\end{array}$ & 0 & & 0 & & 0 & & 0.089 & - & - & - \\
\hline $\begin{array}{r}\text { Small cell } \\
\text { carcinoma }\end{array}$ & 0 & & 0 & & 0 & & & & & \\
\hline $\begin{array}{l}\text { non-small cell } \\
\text { lung cancer }\end{array}$ & 0 & & 0 & & 3 & (33) & & & & \\
\hline \multicolumn{11}{|l|}{ Initial treatment } \\
\hline Surgery & 9 & (90) & 4 & (44) & 2 & (22) & & & & \\
\hline Chemotherapy & 0 & & 2 & (22) & 4 & (44) & $0005 *$ & $0036+$ & 0330 & 1638 \\
\hline Radiation & 1 & (10) & 2 & (22) & 1 & (11) & $0.025^{\circ}$ & 0.0501 & & 1.038 \\
\hline $\begin{array}{r}\text { Best supportive } \\
\text { care }\end{array}$ & 0 & & 1 & (11) & 2 & (22) & & & & \\
\hline
\end{tabular}

* statistically significant by Kruscal-Wallis test.

$\dagger$ statistically significant by Mann-Whitney U test with Bonferroni correction.

$\S$ statistically significant by one-way analysis of variance.

and gastric cancer in 1 patient $(0.04 \%)$. The miss rate of lung cancer detection by cardiologists was calculated to be $52.6 \%$.

The characteristics of the patients with lung cancer in the 3 groups are summarized in Table 3. The mean diameter of tumors for the undetected lung cancer (group P) was 18.5 $5.5 \mathrm{~mm}$, which was significantly smaller than that in groups $\mathrm{C}$ and $\mathrm{H}(\mathrm{p}=0.006)$; whereas there was no difference in tumor diameter between groups $\mathrm{C}$ and $\mathrm{H}$. In addition, tumors in group $\mathrm{P}$ patients were classified as earlier stage tumors than the tumors detected in groups $\mathrm{C}$ and $\mathrm{H}(\mathrm{p}<0.000)$. Group $\mathrm{P}$ tumors also displayed a higher number of superposing structures than group $\mathrm{C}(\mathrm{p}=0.030)$. As a result, the rate of operable cases increased significantly $(\mathrm{p}=0.025)$. Laterality, lobular location, and histology did not differ significantly among the 3 groups.

Fig. 2 shows the distribution of tumor diameter among the 3 groups. The tumor diameter of all lesions in group $\mathrm{P}$ was T1 $(\leq 30 \mathrm{~mm})$. Cardiologists (groups $\mathrm{C}$ and $\mathrm{H}$ ) could detect lesions of $\geq 31 \mathrm{~mm}$ in diameter. 


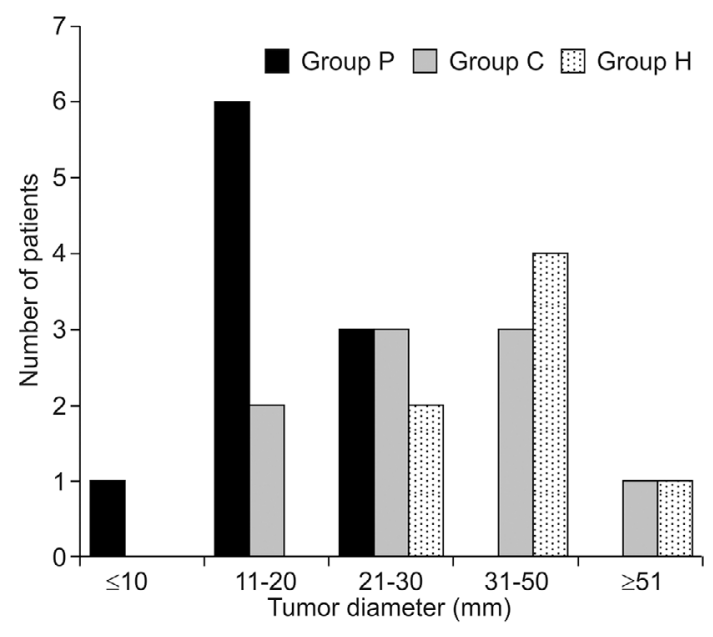

Figure 2. A bar chart showing lung cancer tumor diameter. Group $P$ represents cases in which tumors were detected by the pulmonologists and missed by the cardiologists. Group $\mathrm{C}$ represents the cases in which tumors were detected by a cardiologist alone during the interpretation period. Group $H$ represents the cases in which tumors were detected by cardiologists alone in the historical period.

The rate of patient follow-up was 9.6 and $11.1 \%$ for those in the historical and interpretation periods, respectively. None of these patients developed lung cancer in the followup period.

\section{Discussion}

To our knowledge, no previous studies have reported a clinically-based comparison of the validity of radiographic interpretation of cardiologists and pulmonologists using the same chest radiographs from cardiovascular outpatients. The clinical implication is that additional pulmonologist-based interpretation significantly increased the detection rate of operable lung cancers that were mostly early stage T1 tumors. This result offers a potential clinical benefit by indicating a modality by which the time from patient presentation to the diagnosis of lung cancer may be reduced.

Validity and observer consistency in the detection of lung cancer on chest radiographs varies widely (1). Many factors can account for the inability to detect lung cancer on chest radiographs. Pinto et al. classified 4 factors of radiological errors, including observer errors, interpretation errors, failure to implement appropriate subsequent procedures, and failure to communicate information in a timely and clinically appropriate manner (6). Observer errors are categorized as scanning, recognition, decision-making, and unsatisfactory searching (6-18). Interpretation errors can arise when using multiple sources for a clinical history, or based on the availability of data from previous studies (6). In addition, interpretation errors can be caused by a difference in the index of suspicion, the presence of an abnormality, the reading room environment, and the level of vigilance of the interpreter (6). However, Manning et al. suggested that deci- sional errors rather than detection errors were the major reason for the failed detection of lung cancer on chest radiographs (7). Furthermore, the practitioner's level of experience and practitioner's specialty may influence their diagnostic performance. When comparing the performance of medical practitioners in detecting lung cancer, staff pulmonologists and radiologists have been shown to be more proficient at distinguishing abnormalities than anesthesiologists and resident physicians $(2,3)$.

In the current study, the additional interpretation of chest radiographs by the pulmonologists increased the rate of detection of stage I and surgically resectable lung cancers by 50 and $68.4 \%$, respectively, in comparison to the historical control period. Although, we could not determine whether the cardiologists could not detect abnormal shadows, or whether they detected abnormal shadows but ignored them, we believe that the major reason for the difference of detection ability is their differing perspective. In their examination of a chest radiograph, a cardiologist will focus on the cardiac silhouette, cardiothoracic ratio, chamber enlargement patterns, aortic knob width, pulmonary vascular patterns, flow cephalization, and pleural effusion (11-15). Cardiologists are therefore less likely to pay particular attention to tumor shadows in the lung fields.

While previous studies have shown that tumor distribution can influence the visibility of lung cancer on chest radiographs $(3-5,19-21)$, there was no specific pattern of tumor distribution in the cases that cardiologists were able to or unable to detect (Fig. 3). In the above-mentioned previous studies, undetected lung cancer was predominantly distributed in the periphery of the upper lobes.

Since there was no difference in distribution it is most likely that the tumor size was the most significant factor affecting the ability of cardiologists to detect lung cancer. This was indicated by the poor performance of cardiologists in the detection of lesions of $\leq 30 \mathrm{~mm}$ in diameter (Fig. 2). Tumor size, gradient, and contrast can all influence the visibility of lung cancer on chest radiographs. Previous studies have indicated that the mean diameter of lung tumors on chest radiographs that went undetected ranged from 13-18 $\mathrm{mm}(1,4,9,22-24)$. Conversely, the lower limits at which a radiologist can identify a nodule on a chest radiograph with $90 \%$ accuracy is between $8-10 \mathrm{~mm}$. Only $50 \%$ of $10 \mathrm{~mm}$ tumors are detected by radiologists $(19,25)$.

Yang et al., reported small adenocarcinomas with a lepidic tumor growth pattern to be less visible than those with a solid growth pattern (26). In the current study, 1 case each of ground-glass attenuation-type tumors (T1a) were observed in groups $\mathrm{P}$ and $\mathrm{C}$ and residual cases had solid nodules. Therefore, a T1a lepidic predominant tumor is difficult to detect on chest radiographs, regardless of the physician's specialty.

Poor lesion conspicuity on chest radiographs can be caused by the reduction of tumor visibility by the superimposition of hilar, mediastinal, and bony structures $(6,7)$. In addition, an average of $26.4 \%$ of the lung volume and 


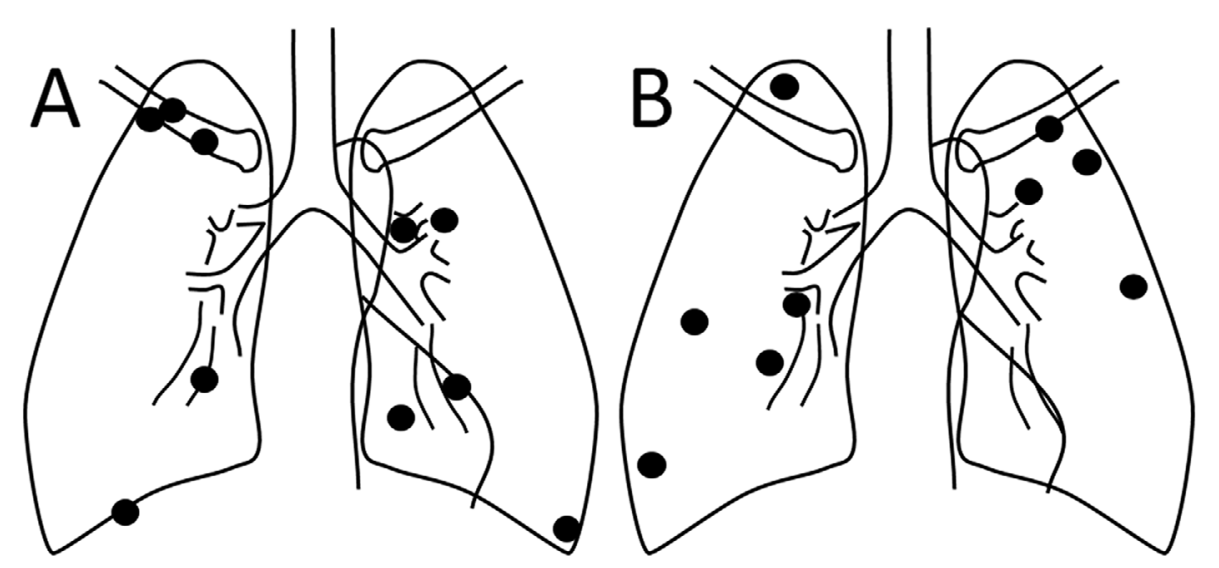

Figure 3. Locations of detected lung cancers in group $P(A)$ and $C(B)$. Although there was no specific pattern of tumor distribution between group $P$ and $C$, tumors in group $P$ had significantly greater proportion of superposing structures.

$43.0 \%$ of the lung area are obscured by the heart, mediastinum, and diaphragm (27), and the complexity of such visual information can cause difficulties in distinguishing between lung cancer and normal anatomical structures (6). Here, $80 \%$ of the lung cancers that were not detected by cardiologists had a significantly greater proportion of superposing structures than those that were detected by cardiologists (Fig. 3).

There are many methods to improve detection of lung nodules on chest radiographs such as computer-aided diagnosis, and the removal or suppression of bony and other anatomical structures (28-33). However, the clinical usefulness and cost-benefit of these techniques for detecting lung cancer remains controversial. It is also debatable whether the failure to detect lung cancer on chest radiographs in these patients adversely affected their prognoses. The studies of Austin et al. (22), and Shah et al. (4) found that prognosis was not necessarily adversely affected by a radiologic miss; however, prognosis is generally influenced by tumor size ( $\mathrm{T}$ factor) and thus is dependent on the length of time by which diagnosis is delayed. According to Quekel et al (1), in $47 \%$ of patients whose lung cancer was not detected, the tumor stage transitioned from T1 to T2. In the current study, the additional interpretation by the pulmonologists increased the detection rate of stage I resectable tumors, which would presumably prevent the transition of tumors by minimizing delays in the diagnosis.

The role of lateral chest radiographs in the detection of lung cancer is controversial, and the detection rate, in comparison to frontal chest radiographs, has been reported to be as low as $2-4 \%(1,6,8,10)$. However, because lateral radiographs were excluded from this study, we cannot comment on the utility of the lateral view in the detection of lung cancer.

The current study is associated with some limitations. It was a retrospective study and the data were collected from a single study center with a low follow-up rate. There were differences in the situations in which cardiologists and pul- monologists performed their interpretations. Furthermore, because chest radiographs were not performed in all new patients, and CT was not performed in all patients with abnormal lung shadows, there may have been cases of lung cancer that were missed by both cardiologists and pulmonologists. This study was also associated with a methodological limitation in that we valued the historical interpretations by cardiologists from medical records. It was therefore impossible to directly compare the validity of interpretations by cardiologists and pulmonologists.

\section{Conclusion}

The additional interpretation of chest radiographs by pulmonologists could therefore be useful for the detection of stage I and surgically resectable lung cancers in cardiovascular patients. Recent digital images can be stored in the Picture Archiving and Communication System (PACS) without information loss. Doctors can access the server easily and read the chest radiographs with the use of image analysis software. Prospective studies using PACS with a longer follow-up period would help to clarify the potential benefits of multidisciplinary analysis of chest radiographs in cardiovascular patients.

The authors state that they have no Conflict of Interest (COI).

\section{References}

1. Quekel LG, Kessels AG, Goei R, van Engelshoven JM. Miss rate of lung cancer on the chest radiograph in clinical practice. Chest 115: 720-724, 1999.

2. Quekel LG, Kessels AG, Goei R, van Engelshoven JM. Detection of lung cancer on the chest radiograph: a study on observer performance. Eur J Radiol 39: 111-116, 2001.

3. Monnier-Cholley L, Carrat F, Cholley BP, Tubiana JM, Arrivé L. Detection of lung cancer on radiographs: receiver operating characteristic analyses of radiologists', pulmonologists', and anesthesiologists' performance. Radiology 233: 799-805, 2004. 
4. Shah PK, Austin JH, White CS, et al. Missed non-small cell lung cancer: radiographic findings of potentially resectable lesions evident only in retrospect. Radiology 226: 235-241, 2003.

5. Potchen EJ, Bisesi MA. When is it malpractice to miss lung cancer on chest radiographs? Radiology 175: 29-32, 1990.

6. Pinto A, Brunese L. Spectrum of diagnostic errors in radiology. World J Radiol 2: 377-383, 2010.

7. Manning DJ, Ethell SC, Donovan T. Detection or decision errors? Missed lung cancer from the posteroanterior chest radiograph. $\mathrm{Br}$ J Radiol 77: 231-235, 2004.

8. Stitik FP, Tockman MS. Radiographic screening in the early detection of lung cancer. Radiol Clin North Am 16: 347-366, 1978.

9. Heelan RT, Flehinger BJ, Melamed MR, et al. Non-small-cell lung cancer: results of the New York screening program. Radiology 151: 289-293, 1984.

10. Muhm JR, Miller WE, Fontana RS, Sanderson DR, Uhlenhopp MA. Lung cancer detected during a screening program using 4month chest radiographs. Radiology 148: 609-615, 1983.

11. Lipton MJ, Boxt LM. How to approach cardiac diagnosis from the chest radiograph. Radiol Clin North Am 42: 487-495, 2004.

12. Hemphill RR, Eisenberg RL. Cardiovascular radiography. Emerg Med Clin North Am 13: 855-885, 1995.

13. Rayner BL, Goodman H, Opie LH. The chest radiograph. A useful investigation in the evaluation of hypertensive patients. Am J Hypertens 17: 507-510, 2004.

14. Thomas JT, Kelly RF, Thomas SJ, Stamos TD, Albasha K, Parrillo JE, et al. Utility of history, physical examination, electrocardiogram, and chest radiograph for differentiating normal from decreased systolic function in patients with heart failure. Am J Med 112: 437-445, 2002.

15. Boxt LM, Reagan K, Katz J. Normal plain film examination of the heart and great arteries in the adult. J Thorac Imaging 9: 208218, 1994.

16. Herman PG, Gerson DE, Hessel SJ, et al. Disagreements in chest roentgen interpretation. Chest 68: 278-282, 1975.

17. Tudor GR, Finlay D, Taub N. An assessment of inter-observer agreement and accuracy when reporting plain radiographs. Clin Radiol 52: 235-238, 1997.

18. Samuel S, Kundel HL, Nodine CF, Toto LC. Mechanism of satisfaction of search: eye position recordings in the reading of chest radiographs. Radiology 194: 895-902, 1995.

19. Kundel $\mathrm{H}$. Predictive value and threshold detectability of lung tumors. Radiology 139: 25-29, 1981.

20. Forrest JV, Friedman PJ. Radiologic errors in patients with lung cancer. West J Med 134: 485-490, 1981.

21. White CS, Salis AI, Meyer CA. Missed lung cancer on chest radiography and computed tomography: imaging and medicolegal issues. J Thorac Imaging 14: 63-68, 1999.

22. Austin JH, Romney BM, Goldsmith LS. Missed bronchogenic carcinoma: radiographic findings in 27 patients with a potentially resectable lesion evident in retrospect. Radiology 182: 115-122, 1982.

23. Sone $\mathrm{S}$, Li F, Yang ZG, et al. Characteristics of small lung cancers invisible on conventional chest radiography and detected by population based screening using spiral CT. Br J Radiol 73: 137$145,2000$.

24. Guiss LW, Kuenstler P. A retrospective review of survey photofluorograms of persons with lung cancer. Cancer 13: 91-95, 1960.

25. Brogdon BG, Kelsey CA, Moseley RD Jr. Factors affecting perception of pulmonary lesions. Radiol Clin North Am 21: 633-654, 1983.

26. Yang ZG, Sone S, Li F, et al. Visibility of small peripheral lung cancers on chest radiographs: influence of densitometric parameters, CT values and tumour type. Br J Radiol 74: 32-41, 2001.

27. Chotas HG, Ravin CE. Chest radiography: estimated lung volume and projected area obscured by the heart, mediastinum, and diaphragm. Radiology 193: 403-404, 1994.

28. Li F, Engelmann R, Doi K, MacMahon H. Improved detection of small lung cancers with dual-energy subtraction chest radiography. AJR Am J Roentgenol 190: 886-891, 2008.

29. Freedman MT, Lo SC, Seibel JC, Bromley CM. Lung nodules: improved detection with software that suppresses the rib and clavicle on chest radiographs. Radiology 260: 265-273, 2011.

30. Vock P, Szucs-Farkas Z. Dual energy subtraction: principles and clinical applications. Eur J Radiol 72: 231-237, 2009.

31. Kakeda S, Moriya J, Sato H, et al. Improved detection of lung nodules on chest radiographs using a commercial computer-aided diagnosis system. AJR Am J Roentgenol 182: 505-510, 2004.

32. Oda S, Awai K, Suzuki K, et al. Performance of radiologists in detection of small pulmonary nodules on chest radiographs: effect of rib suppression with a massive-training artificial neural network. AJR Am J Roentgenol 193: W397-W402, 2009.

33. Szucs-Farkas Z, Schick A, Cullmann JL, et al. Comparison of dual-energy subtraction and electronic bone suppression combined with computer-aided detection on chest radiographs: effect on human observers' performance in nodule detection. AJR Am J Roentgenol 200: 1006-1013, 2013.

(C) 2015 The Japanese Society of Internal Medicine http://www.naika.or.jp/imonline/index.html 